\title{
Konseling Sebaya Sebagai Pencegahan Perilaku Seksual Berisiko Pada Remaja
}

\author{
Sang Ayu Made Adyani', Wiwin Wiarsih' ${ }^{2}$, Poppy Fitriyani ${ }^{3}$ \\ ${ }^{1}$ Fakultas Ilmu Kesehatan Universitas Pembangunan Nasional Veteran Jakarta, \\ ${ }^{2,3}$ Fakultas Ilmu Keperawatan Universitas Indonesia \\ Jl. Margonda Raya, Pondok Cina, Kota Depok. 16424 \\ Email : udek_yani@yahoo.com
}

\begin{abstract}
Abstrak
Remaja merupakan kelompok berisiko yang mempunyai karakteristik tertentu yang berkontribusi menimbulkan masalah kesehatan, salah satunya adalah perilaku seksual berisiko. Tujuan penelitian ini adalah untuk mengetahui hubungan pemanfaatan konseling sebaya dengan perilaku seksual berisiko pada aggregate remaja di Jakarta Selatan. Desain analisis korelasi dengan pendekatan cross sectional digunakan dalam penelitian terhadap 108 responden yang diperoleh melalui simple random sampling. Hasil analisa chi square menunjukkan bahwa ada hubungan yang signifikan pemanfaatan konseling sebaya dengan perilaku seksual berisiko pada aggregate remaja ( $p$ value : 0,003). Hasil penelitian ini menjadi masukan dalam meningkatkan asuhan keperawatan pada aggregate remaja melalui kegiatan konseling sebaya yang lebih memperhatikan kebutuhan perkembangan remaja.
\end{abstract}

Kata kunci : : konseling sebaya, perilaku seksual berisiko, remaja

\begin{abstract}
Adolescent are a risk groups who have certain characteristics which has a contribution that can cause health problem, one of them is a risky sexual behavior. The aim of this research is to know the correlation of the utilization of peer counseling with risky sexual behavior in adolescent aggregate in South Jakarta. The design of correlation analysis with cross sectional method is used in this research to 108 respondent by simple random sampling. The result of this analysis chi square shown that there is a significant correlation of the utilization of peer counseling with risky sexual behavior in adolescent aggregate ( $p$ value :0,003). The results of this study serve as an input in improving nursing care to adolescent aggregate through peer counseling activities that pay more attention to the developmental needs of adolescents.
\end{abstract}

Keywords : adolescent, peer counseling, sexual risk behavior 


\section{Pendahuluan}

Remaja sebagai kelompok berisiko mempunyai karakteristik tertentu yang berkontribusi menimbulkan berbagai masalah kesehatan. Masa remaja merupakan masa peralihan dari masa kanak-kanak menuju masa dewasa, pada masa ini mereka banyak mengalami perubahan baik secara fisik, kepribadian, kognitif, maupun psikososial untuk membentuk identitas diri. ${ }^{1}$ Perubahan yang dialami remaja pada masa pubertas dari segi fisik meliputi perubahan bentuk tubuh, mimpi basah bagi remaja laki-laki dan menstruasi bagi remaja perempuan. Kematangan organ reproduksi juga merupakan dari aspek fisik, biasanya terjadi pada usia 12 tahun pada remaja perempuan dan usia 14 tahun pada remaja laki-laki. ${ }^{2}$

Masa remaja dianggap masa mencari identitas diri dan merupakan masa yang kritis, remaja berusaha melepaskan ketergantungan dari orang tua dan hidup mandiri sehingga dapat diakui sebagai orang dewasa. ${ }^{3}$ Perkembangan sosial yang dialami remaja pada fase ini yaitu terjadi peningkatan hubungan dengan teman sebaya, pada saat yang bersamaan kedekatan hubungan remaja dengan orang tua menurun. ${ }^{4}$, dan remaja lebih banyak menghabiskan sebagian besar waktunya bersama dengan teman sebaya mereka. ${ }^{5}$ Perkembangan sosial remaja yang mudah terpengaruh oleh teman sebaya mengakibatkan remaja kehilangan identitas sosial sehingga remaja semakin berisiko terhadap masalah kesehatan. ${ }^{6}$

Remaja juga mengalami perkembangan fisik dan hormonal. Remaja yang kurang mampu beradaptasi terhadap perubahan fisik dan hormonal akan memperlihatkan perilaku berisiko yang mengancam kesehatan, seperti aktivitas seksual yang terlalu dini. ${ }^{6}$ Perilaku seksual berisiko yaitu hubungan seks yang berganti-ganti pasangan, di luar nikah yang menyebabkan kehamilan yang tidak diinginkan (KTD), aborsi dan terjangkitnya penyakit infeksi seksual, HIV dan AIDS, infertilitas, dan keganasan. ${ }^{7}$

Mengantisipasi permasalahan yang terjadi pada remaja, pemerintah melalui Kementerian Kesehatan telah mengeluarkan kebijakan terkait kesehatan remaja yaitu Program Pelayanan Kesehatan Peduli Remaja (PKPR) melalui teman sebaya, konselor sebaya dan edukator sebaya dalam upaya promosi kesehatan pada remaja. Program lain yang juga berupaya dalam mengatasi kesehatan reproduksi dikalangan remaja dilakukan oleh BKKBN melalui Pusat Informasi dan Konseling Kesehatan Reproduksi Remaja (PIKKRR). Pelaksanaan kedua program diatas dilakukan melalui pemberdayaan remaja yaitu konseling sebaya.

Peran pendidik dan konseling sebaya dapat memberikan pengaruh baik bagi remaja. Peran edukator sebaya dengan metode adolescent friendly menunjukkan bahwa edukator sebaya dapat memberikan pengaruh positif pada agregat remaja perempuan dalam meningkatkan kemampuan untuk mencegah perilaku berisiko terhadap kehamilan remaja di SMP Ratu Jaya Kota Depok. ${ }^{8}$ Penyampaian pendidikan kesehatan reproduksi oleh kelompok sebaya (peer group) terbukti meningkatkan pengetahuan reproduksi remaja. ${ }^{9}$

Namun, perilaku seksual pada remaja meningkat dari tahun ke tahun. Hasil penelitian pada 500 remaja di Asia usia 11-19 tahun, sebanyak $60,7 \%$ telah melakukan hubungan seksual dengan pasangannya kurang dari satu bulan yang lalu dan $8 \%$ lebih dari 6 bulan sebelumnya. ${ }^{10}$ Perilaku seksual pada 2756 remaja 2756 Thailand, sebanyak $11,0 \%$ remaja melakukan hubungan seksual dalam waktu 12 bulan terakhir. Rentang usia remaja tersebut 1217 tahun, $14,6 \%$ pada remaja laki-laki, dan $7,6 \%$ pada remaja perempuan ${ }^{11}$. Hasil penelitian pada 1500 remaja di China, sebanyak 12,6 remaja pernah melakukan hubungan seksual, $10,8 \%$ pernah melakukan oral sex, dan $46 \%$ remaja melakukan masturbasi. ${ }^{12}$

Kejadian seks pranikah pada remaja di Indonesia ditunjukkan oleh beberapa penelitian. Penelitian di kota Bandung pada tahun 2008 oleh 25 Messenger Jawa Barat menunjukkan bahwa 56\% dari 100 responden remaja pernah melakukan hubungan seksual, dimana usia mereka 15-24 tahun. Dari survey yang sama diketahui pula $30 \%$ remaja melakukan hubungan seks dengan pacarnya sendiri, $11 \%$ dengan pekerja seks komersial, 3\% dengan orang yang baru dikenalnya, dan $40 \%$ ternyata berganti-ganti pasangan. ${ }^{13}$

Drotar et al (2000, dalam Santrock, 2007) mengatakan bahwa remaja jarang memanfaatkan pelayanan kesehatan yang ada. Berdasarkan hasil Study of Adolescent Health terhadap lebih dari 12.000 remaja yang diwawancarai tentang kebutuhan perawatan kesehatan, sekitar 19\% mengunjungi pelayanan 
kesehatan satu tahun yang lalu. ${ }^{14}$ Kelompok yang dianggap khusus membutuhkan perawatan kesehatan namun tidak menggunakannya adalah para remaja yang mempunyai kebiasaan merokok, sering mengkonsumsi alkohol, dan melakukan hubungan seksual. Studi Nasional di Amerika Serikat menemukan bahwa, laki-laki yang berusia 16-20 tahun secara signifikan lebih jarang menggunakan layanan kesehatan dibandingkan dengan laki-laki yang berusia 1115 tahun. Namun sebaliknya, pada perempuan yang berusia 16-20 tahun lebih banyak mengunjungi layanan kesehatan dibandingkan dengan perempuan yang lebih muda.

Beberapa hambatan utama remaja dalam mendapatkan layanan kesehatan yang lebih baik adalah biaya, organisasi yang kurang baik dan kurangnya layanan kesehatan, kurangnya kerahasiaan, dan keengganan para penyedia layanan kesehatan untuk membahas isu-isu kesehatan yang sensitif dengan remaja, sementara hanya beberapa tenaga kesehatan yang mendapatkan latihan khusus dalam menangani remaja. ${ }^{14}$ Orang tua mengungkapkan ketidaknyamanan dialami remajanya saat mendiskusikan tentang topiktopik seksualitas atau obat terlarang, sehingga mereka sangat menghindari diskusi-diskusi tersebut.

\section{Metode}

Penelitian ini merupakan penelitian kuantitatif dengan desain deskriptif korelasi menggunakan metode pendekatan cross sectional. Penelitian ini terdiri dari variabel independen (pemanfaatan konseling sebaya) dan variabel dependen (perilaku seksual berisiko). Populasi dalam penelitian ini adalah seluruh remaja yang tinggal di Kelurahan Pasar Minggu Jakarta Selatan, dengan jumlah sampel 108 responden. Kriteria inklusi dari penelitian ini adalah remaja yang berusia 10-19 tahun dan belum menikah, berdomisili di Kelurahan Pasar Minggu Jakarta Selatan, bersedia menjadi responden penelitian, bisa membaca dan menulis, pernah menggunakan konseling sebaya. Pengumpulan data pada penelitian ini menggunakan instrument penelitian yaitu kuesioner. Kuesioner yang digunakan dalam penelitian ini disusun oleh peneliti sendiri berdasarkan teori-teori yang terkait dengan konseling sebaya, dan perilaku seksual berisiko pada aggregate remaja, dan telah dilakukan uji validitas. Remaja diberikan waktu 90 menit untuk mengisi kuesioner. Data yang telah terkumpul kemudian dianalisis univariat dan bivariat (chi square).

\section{Hasil}

\section{Gambaran Karakteristik Remaja}

Distribusi Karakteristik Remaja Berdasarkan Umur, Jenis Kelamin, dan Tingkat Pendidikan menunjukkan bahwa sebanyak 51 responden $(47,2 \%)$ berada pada umur 10-14 tahun dan sebanyak 57 responden $(52,8 \%)$ berada pada umur 15-19 tahun. Sebanyak 52 responden $(48,1 \%)$ adalah perempuan, dan sebanyak 56 responden $(51,9 \%)$ adalah lakilaki. Berdasarkan tingkat pendidikan lebih dari separuh responden memiliki tingkat pendidikan tinggi (SMA \& PT) yaitu sebanyak 55 responden $(51,0 \%)$.

\section{Gambaran Pemanfaatan Konseling Sebaya}

Distribusi Pemanfaatan Konseling Sebaya Pada Aggregate Remaja menunjukkan bahwa sebanyak 58 remaja $(53,7 \%)$ pemanfaatan konseling sebaya baik dan sebanyak 50 remaja $(46,3 \%)$ pemanfaatan konseling sebaya kurang baik.

\section{Gambaran Perilaku Remaja}

Distribusi Perilaku Seksual Berisiko Pada Aggregate Remaja menunjukkan bahwa sebanyak $53,7 \%$ responden memiliki pengetahuan rendah, 53,7\% memiliki sikap negatif, dan 57,4\% mempunyai tindakan yang kurang baik. Perilaku seksual berisiko pada aggregate remaja di Kelurahan Pasar Minggu Jakarta Selatan mempunyai proporsi yang lebih besar $(60,2 \%)$ dibandingkan dengan perilaku seksual tidak berisiko $(39,8 \%)$. Perilaku seksual pada remaja dalam penelitian ini merupakan hasil dari domain pengetahuan, sikap, dan tindakan yang dikompositkan menjadi satu dalam perilaku seksual remaja.

\section{Hubungan Pemanfaatan Konseling Sebaya dengan Perilaku Seksual Berisiko}

Hubungan Pemanfaatan Konseling Sebaya Dengan Perilaku Seksual Berisiko Pada Aggregate Remaja menunjukkan bahwa proporsi remaja yang berperilaku seksual berisiko dengan pemanfaatan konseling sebaya yang kurang baik sebanyak $66,2 \%$ lebih besar dibandingkan dengan remaja yang memiliki berperilaku berisiko dengan pemanfaatan konseling sebaya baik sebesar $33,8 \%$. Hasil 
hipotesis Chi Square menunjukkan nilai $p$ value 0,003 dengan nilai $\alpha=0,05$, sehingga $\mathrm{H}_{\mathrm{o}}$ ditolak. Hal ini menunjukkan bahwa ada hubungan yang bermakna antara pemanfaatan konseling sebaya dengan perilaku seksual pada aggregate remaja. Hasil interpretasi OR adalah remaja dengan pemanfataan konseling sebaya yang kurang baik mempunyai kemungkinan 3,648 kali berperilaku seksual berisiko daripada remaja yang memanfaatkan konseling sebaya dengan baik.

\section{Pembahasan}

\section{Pemanfaatan Konseling Sebaya}

Hasil analisis menunjukkan bahwa sebanyak $53,7 \%$ pemanfaatan konseling sebaya kurang baik dan sebanyak $46,3 \%$ responden memanfaatkan konseling sebaya dengan baik. Hasil penelitian ini sejalan dengan pendapat Drotar et al (2000, dalam Santrock 2007) bahwa remaja jarang memanfaatkan pelayanan kesehatan yang ada ${ }^{14}$. Berdasarkan hasil Study of Adolescent Health terhadap lebih dari 12.000 remaja yang diwawancarai tentang kebutuhan perawatan kesehatan, sekitar 19\% mengunjungi pelayanan kesehatan satu tahun yang lalu. Kelompok yang dianggap khusus membutuhkan perawatan kesehatan namun tidak menggunakannya adalah para remaja yang mempunyai kebiasaan merokok, sering mengkonsumsi alkohol, dan melakukan hubungan seksual.

Masa remaja diyakini sebagai individu yang mencapai tingkat kesehatan, kekuatan, dan energi. Remaja juga memiliki keyakinan sebagai sosok yang unik dan kebal yang tidak akan pernah sakit, atau seandainya mereka jatuh sakit akan segera pulih dibandingkan dengan kelompok umur lainnya. ${ }^{14} \mathrm{Hal}$ ini menyebabkan remaja jarang memanfaatkan pelayanan kesehatan yang ada.Hasil penelitian menunjukkan sebesar $9,3 \%$ remaja menganggap konselor sebaya tidak bisa menyimpan rahasia. Hambatan utama remaja dalam memperoleh layanan kesehatan adalah kurangnya kerahasiaan para petugas kesehatan dan organisasi yang kurang baik. ${ }^{14}$

Hasil penelitian Sylviani (2008) tentang layanan konseling oleh remaja melalui pendekatan kualitatif bahwa beberapa alasan siswa remaja tidak memanfaatkan konseling sebaya karena siswa tersebut belum dekat dengan konselor sebaya, tidak percaya dengan kemampuan konselor untuk membantu menyelesaikan masalah mereka, dan karena siswa tersebut tidak mengetahui keberadaan konselor sebaya. ${ }^{15}$

\section{Gambaran Perilaku Seksual Berisiko}

Berdasarkan pengetahuan remaja yang masih kurang yaitu sebanyak $53,7 \%$ dan yang berpengetahuan baik sebesar 46,3\%. Pengetahuan yang diukur dalam penelitian ini yaitu definisi serta dampak dari perilaku seksual berisiko. Pengetahuan remaja yang berbedabeda disebabkan oleh interaksi dengan lingkungannya. Menurut Notoatmodjo (2007) pengetahuan merupakan hasil dari tahu yang diperoleh dari pengindraan panca indra manusia ${ }^{15}$. Pengetahuan merupakan predisposisi dari perilaku dan gambaran pengetahuan dapat memberi isyarat perilaku.

Menurut BKKBN (2010) kurangnya pengetahuan remaja tentang kesehatan reproduksi dan perilaku seksual membuat remaja tidak memiliki kendali untuk menolak perilaku seks bebas dan menyebabkan remaja sangat rentan terhadap penyakit menular seksual dan kehamilan yang tidak diinginkan. Pada masa remaja terjadi perubahan hormon yang sangat besar sehingga menimbulkan dorongan seks yang besar. Remaja dengan pengetahuan yang kurang tentang dampak dari perilaku seksual membuatnya mengambil keputusan yang salah salah satunya melakukan perilaku seksual berisiko. ${ }^{17}$ Namun, menurut Notoatmodjo (2010) pengetahuan bukanlah satu-satunya domain yang menentukan perilaku, domain lain yang menentukan perilaku adalah sikap dan ketrampilan. ${ }^{18}$

\section{Hubungan Pemanfaatan Konseling Sebaya dengan Perilaku Seksual Berisiko Pada Remaja}

Pelaksanaan konseling sebaya dilakukan oleh konselor sebaya yang mampu memberikan informasi tentang kesehatan dan membantu teman sebaya untuk mengenali masalahnya, sehingga mampu mengambil keputusan yang tepat ${ }^{19}$. Menurut Varenhorst (1976, dalam Hunainah, 2004) konseling sebaya merupakan suatu upaya untuk mempengaruhi perubahan sikap dan perilaku yang cukup efektif untuk membantu remaja dalam menyelesaikan masalahnya sendiri. ${ }^{20}$

Konselor sebaya adalah pendidik sebaya yang diberikan pelatihan tambahan interpersonal relationship dan konseling. Jadi 
konselor sebaya juga melakukan pendidikan kesehatan kepada teman sebayanya sehingga dapat meningkatkan pengetahuan remaja tentang perilaku seksual. Hal ini sejalan dengan penelitian Achjar (2006) bahwa penyampaian pendidikan kesehatan reproduksi remaja melalui peran kelompok sebaya (peer group) setelah dilakukan intervensi selama 3 kali pertemuan (dalam 3 minggu) terbukti meningkatkan pengetahuan reproduksi remaja dengan menggunakan metode kuasi eksperimen. ${ }^{8}$

Pendidikan kesehatan oleh pendidik sebaya merupakan salah satu pendekatan yang sering digunakan untuk mempengaruhi perubahan pengetahuan pada tingkat kelompok. Perubahan yang terjadi dipengaruhi oleh pembawa pesan, dimana pembawa pesan yang berasal dari kelompoknya memiliki pengaruh kuat dalam menarik perhatian kelompok. ${ }^{22} \mathrm{Jika}$ yang memberikan informasi adalah orang yang lebih dewasa akan dapat menimbulkan kesenjangan dalam penggunaan istilah, gaya bicara, sehingga menghambat arti pesan yang disampaikan.

\section{Kesimpulan}

Lebih dari separuh remaja kurang baik memanfaatkan konseling sebaya yang ada di wilayah mereka dan lebih dari separuh remaja melakukan perilaku seksual berisiko, hal ini diperoleh berdasarkan tiga domain perilaku yaitu pengetahuan tentang perilaku seksual dan sikap yang rendah, serta tindakan yang kurang baik. Terdapat hubungan yang bermakna antara pemanfaatan konseling sebaya dengan perilaku seksual berisiko. Remaja dengan pemanfaatan konseling sebaya yang kurang baik mempunyai kemungkinan 3,648 kali berperilaku seksual berisiko dibandingkan remaja yang memanfaatkan konseling dengan baik.

\section{Saran}

Perawat diharapkan dapat melakukan pengkajian secara mendalam tentang kebutuhan informasi pada rentang usia yang berbeda. Pendidikan kesehatan yang diberikan kepada remaja agar sesuai dengan tahap tumbuh kembang.

Perawat diharapkan mampu memberikan asuhan keperawatan kepada keluarga yang memiliki anak remaja mengenai tumbuh kembang remaja dan tugas perkembangan keluarga dengan anak remaja. Keluarga yang memiliki anak remaja mampu menciptakan suasana yang nyaman dan sesuai dengan kebutuhan remaja sehingga remaja tidak menghabiskan waktunya di luar rumah. Penanaman nilai dan norma sejak dini di rumah sehingga remaja dapat berperilaku hidup sehat.

Perawat yang bekerja di institusi layanan kesehatan/Puskesmas diharapkan dapat membina melalui pelatihan-pelatihan maupun pendidikan kesehatan kepada konselor sebaya agar mampu melakukan konseling dan informasi kesehatan kepada remaja, serta mampu menjaga kerahasiaan konseli. Klinik PKPR disesuaikan dengan perkembangan remaja, dan remaja yang ingin berkonsuktasi tidak diperlakukan sama seperti pasien lainnya, agar remaja merasa nyaman dan terjamin kerahasiaannya. Penelitian ini dapat menjadi masukan dalam melakukan penelitian selanjutnya dengan menggunakan pendekatan kualitatif mengenai perilaku seksual berisiko maupun pemanfaatan konseling oleh remaja.

\section{Daftar Pustaka}

1. Papalia, D.E., Old, S.W., \& Feldman, F.D. Human development. The McGraw Hill Companies; 2008.

2. Kozier et al. Fundamental Of Nursing : Concept, Process and Practice. $7^{\text {th }}$ Ed. Upper Saddle River : Perason Education Inc; 2004.

3. Friedman, M.M., Bowden,V.R., \& Jones, E.G. Family Nursing: Research Theory \& Practice. New Jersey : Prentice Hall; 2003.

4. Santrock, J.W. Life-Span Development. Ninth Edition. Boston : McGraw-Hill Companies; 2004.

5. Steinberg, L. Adolescence. New York : Mc. Graw-Hill, Inc; 1993.

6. Mc.Murray, A. Community Health and Wellness : A Sociological Approach. Toronto : Mosby; 2003.

7. Depkes, RI. Modul Pelatihan Pelayanan Kesehatan Peduli Remaja (PKPR). Jakarta : Departemen Kesehatan RI; 2007.

8. Achjar, K.A.H. Pengaruh Penyampaian Pendidikan Kesehatan Oleh Kelompok Sebaya (Peer Group) Terhadap Pengetahuan Kesehatan Reproduksi Remaja di Kelurahan Kemiri Muka Depok. Tesis. FIK UI Depok; 2006.

9. Wong, et al. Premarital Sexual Intercourse Among Adolescent in an Asian Country : Multilevel Ecological Factors. Pediatrics; 2005. Vol 124, e44.

10. Peltzes, K., \& Pengpid, S. Prevalence and Social Correlates of Sexual Intercourse Among School-Going Adolescents in Thailand. The Scientific Journal; 2011.11, 1812-1820. 
11. Chi, et al. Prevalence and Correlates of Sexual Behaviors Among University Students : a study in Hefei, China. BMC Public Health 2012, 12 : 97.

12. BKKBN. Profil Pendidikan, Kesehatan, Dan Sosial Remaja Bandung : masalah dan Alternatif Solusinya; 2010.

13. Santrock, J.W. Life-Span Development. Ninth Edition. Boston : McGraw-Hill Companies; 2007.

14. Sylviani, M. Pelayanan Konseling Oleh Konselor Sebaya di SMAN 3 dan MAN 2 Di Kota Bogor. Skripsi. Fakultas Kesehatan Masyarakat Universitas Indonesia; 2008.

15. Notoatmodjo, Soekidjo. Promosi Kesehatan dan Ilmu Perilaku.PT Rineka Cipta. Jakarta; 2007.

16. Sarwono, S. W. Psikologi Remaja. Jakarta : Rajawali Pers; 2011.
17. Notoatmodjo. Promosi Kesehatan Teori dan Aplikasi. Jakarta : Rineka Cipta; 2010.

18. Kementrian Kesehatan RI. Pedoman Teknik Konseling Kesehatan Remaja Bagi Konselor Sebaya. Jakarta : Direktorat Jenderal Bina Kesehatan Masyarakat; 2010.

19. Hunainah. Teori dan Implementasi Model Konseling Sebaya. Jakarta : Rizky Press; 2004.

20. McDonald, et al. peer education form evidenced to practice : an alcohol \& other drugs primer (2003; http://www.nceta.flinders.edu.au/pdf/peereducation/entire-monograph.pdf, diperoleh tanggal 4 Juni 2013). 